\title{
Cefepime versus Ceftriaxone for perioperative systemic antibiotic prophylaxis in elective orthopedic surgery at Bugando Medical Centre Mwanza, Tanzania: a randomized clinical study
}

\author{
Joel M. Marwa ${ }^{1}$, Isidor H. Ngayomela², Jeremiah Seni ${ }^{3}$ and Stephen E. Mshana ${ }^{3 *}$
}

\begin{abstract}
Background: Antimicrobial prophylaxis reduces the incidence of postoperative wound infections especially among patients undergoing orthopedics surgery. However, there is dearth of information on the clinical effectiveness, spectrum limitations and practical contextual information on third and fourth generation cephalosporins. The aim of this study was to evaluate the efficacy and safety of cefepime and ceftriaxone as peri-operative systemic antimicrobial prophylaxis in elective orthopedic surgery in our center.
\end{abstract}

Methods: This study was a prospective, randomized, open label comparative clinical study of patients undergoing elective orthopedic procedures at the Bugando Medical Centre (BMC) between June 2014 and February 2015. Two hundred thirty participants were enrolled in the study and randomly assigned into Ceftriaxone regimen (group A) or Cefepime regimen (group B). Participants in ceftriaxone or cefepime group received $50 \mathrm{mg} / \mathrm{kg}$ up to $2 \mathrm{~g}$ single dose perioperative intravenous infusion at least 30 min before incision. Both groups were followed for 30 days using a Center for Disease Control superficial surgical site infection criterion for the outcome. A two-tailed margin of equivalence was set at $5 \%$ analyzed on the intent to treat.

Results: All 230 participants were subjected to final analysis with no patient being lost to follow-up. Superficial surgical site infection occurred in 5 out of $117(4.3 \%, 0.6$ to 7.9 at $95 \%$ Cl) patients receiving cefepime compared to 3 out of $113(2.7 \%, 0.3$ to 5.6 at $95 \% \mathrm{Cl})$ among patients receiving ceftriaxone regimen. The absolute difference of $1.6 \%$ (95\% Confidence Interval: -6.3 to 3.1 ), equivocally lies outside the $5 \%$ statistically significant margin of presumed clinical equivalence.

Conclusion: The difference between cefepime and ceftriaxone in preventing SSIs following elective clean orthopedic surgery was not statistically significant.

Trial Registration: Pan African Clinical Trial Registry: PACTR201406000803420

Keywords: Surgical Site Infection, Ceftriaxone, Cefepime, Mwanza, Tanzania

\footnotetext{
* Correspondence: mshana72@yahoo.com

${ }^{3}$ Department of Microbiology/Immunology, Catholic University of Health and

Allied Sciences (CUHAS), P.O. BOX 1464, Mwanza, Tanzania

Full list of author information is available at the end of the article
} 


\section{Background}

Surgical site infections (SSIs) continue to be a major source of morbidity and mortality in developing and resource limited countries despite advances in aseptic techniques [1-4]. Orthopedic patients especially for those who require corrective surgical procedures have a greater risk of surgical site infections [5]. SSIs are important complications of orthopedic procedures often associated with prolonged length of hospital stay, high incidence of readmission, huge treatment costs and low quality of life [6].

The principles of prophylaxis against post-surgical infection have been established and the administration of antibiotics within 60 min prior to surgery is now widely accepted [7]. The choice of perioperative prophylactic antibiotics follows the principles that the selected regimen should target microbial agents commonly involved in surgical site contamination and definite infection. In orthopedics surgery seeding of the operative site from a distant site of infection can also occur especially in patients with prosthesis or other implants [8].

Evidence has shown that a single dose cephalosporin prophylaxis leads to a significant reduction in the proportion of developing surgical site infections, and is adequate in orthopedic surgical procedures [9-12]. A latest Cochrane systematic review reported that perioperative prophylaxis during the operative management of closed fractures reduce infection rates from around $5 \%$ to less than $1 \%$ [13].

Recently, after the introduction of cefepime in Tanzania, clinicians started prescribing it in the place of previously favored regimes such as ceftriaxone, penicillins and aminoglycosides [14]. However, at Bugando Medical Centre (BMC), the prophylactic efficacy of cefepime over other cephalosporins or other prophylactic regimens remains unknown, especially in our trauma and orthopedic surgery.

No standard or written guidelines exist in our centre to direct the choice of effective or appropriate antimicrobial regimen for use as perioperative prophylaxis during elective orthopedic surgery. Therefore, this study was performed to compare the efficacy of cefepime and ceftriaxone for systemic perioperative prophylactic use in elective orthopedic surgery at BMC.

\section{Methods}

\section{Study design}

This study was a comparative, open label, prospective randomized clinical trial. It was performed to compare the efficacy, of a single dose prophylactic cefepime and ceftriaxone among patients underwent elective orthopedic surgery at BMC, Mwanza Tanzania.

\section{Study population}

The study population included all patients admitted at the BMC orthopedic wards and planned for elective orthopedic surgical procedure between June 2014 and February 2015 [15]. All orthopedic patients between 1 and 70 years of age planned for elective orthopedic surgery were considered eligible. However, patients with open contaminated fractures, history of any antibiotic use within 7 days preceding surgery, known history of hypersensitivity to beta-lactams, immunodeficiency disorders, HIV infection, pregnancy, diabetes or existing infection of soft tissue, bone or at the site of the fracture were excluded from the study.

\section{Sample size estimation}

The sample size was estimated using the formula published by Altman [16] and as used by Noordzij et al. [17]. The expected SSI rate estimates for ceftriaxone and cefepime were $2.3 \%$ and $1.1 \%$ respectively among patients as published by Del Rio et al. [18]. The conventional multipliers for alpha $=0.05$ and multiplier for power $=0.90$ were used and we considered a pre-study difference of more than $5 \%$ between the two groups to be statistically significant. The sample size obtained was 208 patients (a minimum of 104 participants per group) and $10 \%$ of this estimate was added to cover for nonresponse or loss to follow up, thus the required minimum sample size became 230 patients.

\section{Randomization}

Participants were assigned to one of two treatment groups, designated as "A" (ceftriaxone) and "B" (cefepime) using four digits, randomly generated computer numbers. Randomization to the two study arms was at 1:1 ratio. Each patient received $50 \mathrm{mg} / \mathrm{kg}$ (maximum $2 \mathrm{~g}$ ) intravenous antibiotic given within $30 \mathrm{~min}$ before surgery. In case surgery lasted beyond $4 \mathrm{~h}$ or blood loss, surpassed $1500 \mathrm{~mL}$ the dose was repeated.

\section{Null hypothesis}

The treatment difference on the proportion of elective orthopedic surgery SSI in the two arms should be less or equal to $\pm 5 \%$.

\section{Alternative hypothesis}

The treatment difference on the proportion of elective orthopedic surgery SSI in the two arms should be more than $\pm 5 \%$.

\section{Explanatory variables}

Independent variables were demographic data (e.g. age, sex, and occupation), clinical presentation, ASA classification, type of orthopedic surgical procedure and implants used. In addition, duration of procedure, blood 
loss, type of anesthesia, wound closures, placement or removal of internal or external implants, and use of drains were also included.

\section{Primary outcome measure}

Surgical site infection was the primary end point carried out between day 3 and 30 after surgery. Two members of the orthopedic team alien to the study provided surveillance and clinical diagnosis of surgical site infection in the ward or SOPD. The CDC criteria of wound infection occurring at the incision site within 30 days after surgery and involving the skin, subcutaneous tissue, or muscle located above the fascial layer formed the basis for SSIs surveillance was used [19].

Surveillance continued for 30 days by making telephone calls and if patients reported any symptoms of wound infection patients were requested to return to the hospital for re-examination and specimen collection.

\section{Microbiology laboratory studies}

Wound discharge or pus were collected from infected surgical incisions using sterile cotton swabs without contaminating with skin commensals and was placed in a sterile bottle with transport media (Oxoid, UK). Collected samples were transported to laboratory within $1 \mathrm{~h}$ after being obtained. In the laboratory, specimens were registered and processed following standard laboratory procedures (SOPs) [20].

Isolates were identified using in-house biochemical tests as previously described [21, 22]. All isolates were subjected to antimicrobial drug susceptibility testing using disk diffusion method as stipulated by the Clinical Laboratory Standard Institute (CLSI) guidelines [23].

\section{Data collection}

Data were recorded on three different data sheets coded as Data Sheets A, B, and C. Data Sheet A focused on Contact information, socio-demographic information of the patient, morbid history and preoperative laboratory test results. The explanatory data captured included: age, gender, mechanism of injury, time to treatment, medical history and prior treatments, co-morbidities, smoking, alcohol use, andrecent history of antibiotic use. The attending doctor collected on or near the day of admission this information.

Sheet B contained intra-operative data regarding the treatments option for each injury, including the dates of the treatments, types of procedures, operative time, and blood loss, type of anesthesia, wound closure options, placement or removal of internal or external implants. This information on data sheet B was collectedintraoperatively corroborating with real time medical records by anesthetic and nursing staff.
Data Sheet $C$ contained postoperative surveillance and follow-up information regarding progress, and subsequent treatment outcomes. In addition, the PI and researchassistants did transcribed phone conversations and completed progress charts during scheduled SOPD clinic visits.

\section{Data management and statistical data analysis}

Data were entered and cleaned using SPSS $^{\circ}$ version 21 (IBM Corporation) and re-assigned into STATA ${ }^{\circ}$ Version 11 for analysis. The analysis of data involved hypothesis testing and comparison of study outcomes between cefepime and ceftriaxone groups. A statistical difference was established for a significant difference in cumulative incidence of surgical site infection between patients undergoing elective orthopedic surgery receiving perioperative e ceftriaxone and cefepime regimen. Four parameters- cumulative incidence, incidence rate, $95 \%$ confidence intervals and $P$-values were used to delineate results. Fisher's Exact Test and $P$-value of analyzed data $<$ 0.05 was considered to be statistically significant.

Cumulative incidence was calculated as the proportion of cases with SSI noted over total number of participants in each regimen under study. Incidence rate was computed by dividing the number of study subjects manifesting wound infection with total person follow-up days. Proportion test was done to determine the $95 \%$ CI of the rates of SSI in two arms.

Data were summarized in form of proportions, and frequency tables, for categorical variables, while measures of central tendency were used to summarize continuous variables.

\section{Ethical clearance}

This trial did not involve new drugs but only determined the efficacy of a single dose regime of ceftriaxone and cefepime, however GCP and Declaration of Helsinki were observed. The study was cleared by CUHAS/BMC Research Ethics Committee with certificate no CRE/010/ 2014. An informed consent was obtained from participants after explaining the rationale of the study.

\section{Results}

\section{Number of patients recruited}

A total of 248 patients who were planned to undergo elective orthopedic surgery were assessed for eligibility between June 2014 and February 2015. Fourteen were excluded for failure to meet the inclusion criteria, while four candidates declined to consent for enrollment into the clinical trial. Consequently, 230 patients were recruited and randomized into ceftriaxone (Group A, 113 patients) and cefepime (Group B, 117 patients) as shown in Fig. 1. 


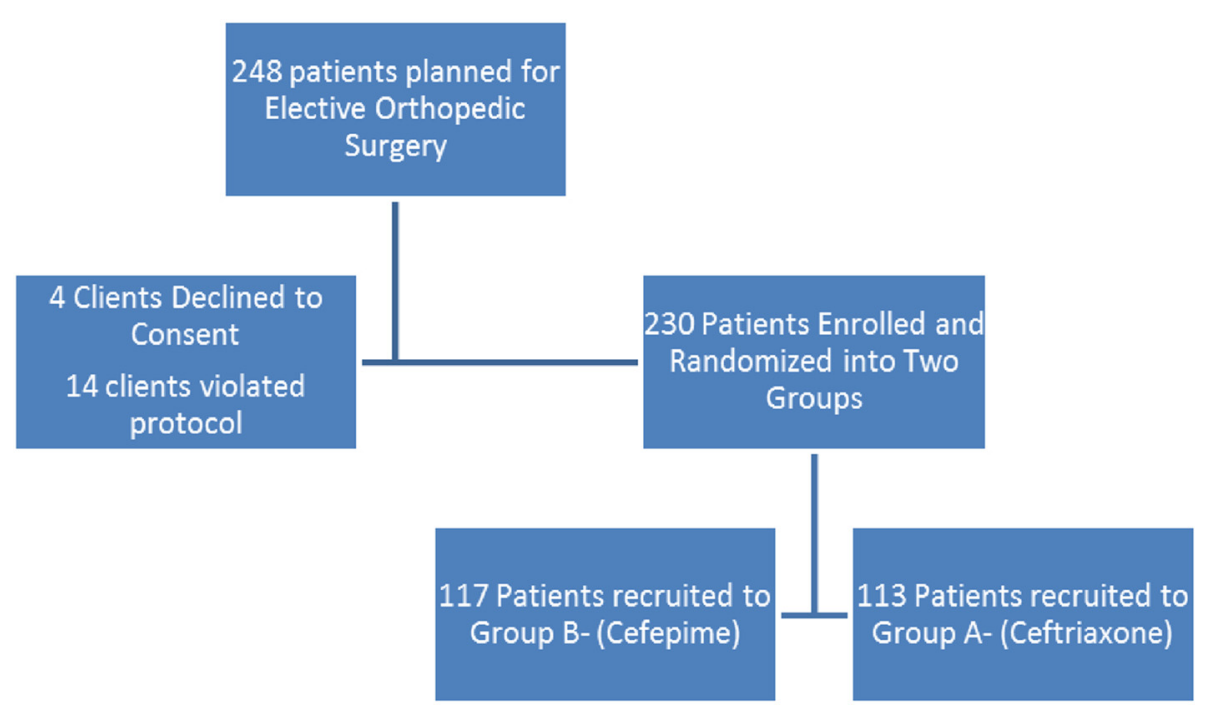

Fig. 1 Flow chart showing disaggregated number of participants

\section{Demographic characteristics of the study population}

There was an even distribution of the participants with respect to demographic and other baseline characteristics in group A and group B $(p$-value $>0.05)$ as shown in Table 1.

\section{Pre-operative clinical presentation}

Even distribution of pre-operative clinical characteristics was observed in both arms except for site of lesion and time taken before definitive treatment was given $(p$-value $<0.05)$ as seen in Table 2.

\section{Intra-operative clinical presentation}

No statistical differences were observed in the distribution of intra-operative clinical characteristics in both groups as seen in Table 3.

\section{Clinical outcomes}

Increasing tenderness at surgical site after discharge from ward was reported among $3(2.6 \%)$ patients in cefepime group and $1(0.9 \%)$ patient in the ceftriaxone arm. Four clients in-group B demonstrated fever $>$ $38.5{ }^{\circ} \mathrm{C}$ during the follow up period while 112 (99.1\%) in group A and 112 (95.7\%) in-group B schedule did not report any event during routine enquiry or follow up Table 4.

\section{Incidence of SSI in elective surgery}

Among 230 clients 8 (3.47\%) developed superficial surgical site infections. The disaggregated incidence in the ceftriaxone group was $2.7 \%$ [95 \% CI 0.3-5.6) compared to $4.3 \%$ (95\% CI 0.6-7.9) for patients enrolled into the cefepime group $(P=0.380)$ as shown in Table 4 . The probability of developing superficial SSI decreased over time manifested as wound dehiscence and positive culture as shown in Kaplan Cox and Meier survival graph (Fig. 2).

\section{Efficacy of cefepime over ceftriaxone regimen}

The incidence rate was calculated as person days for both arms of clinical study. In this study the incidence rate of superficial surgical site infection were 0.9 and 1.45 per 1000 person days in group A (ceftriaxone) and group B (cefepime) regimes respectively $(p=0.380)$ Table 5.

\section{Bacterial isolates}

As empirical proof of infection, bacterial isolates were necessary and useful in the choice of antimicrobial among patients presenting with clinical features of SSIs. The bacteriological isolates in the ceftriaxone group were Staphylococcus aureus, Pseudomonas aeruginosa and Coagulase negative Staphylococcus. In-group B (cefepime) regimen, bacteriological isolates were Staphylococcus aureus, Coagulase negative Staphylococcus, Proteus spp., Klebsiella pneumoniae and 1 unidentified gram negative bacteria.

All bacterial isolates in ceftriaxone and cefepime groups were sensitive to ciprofloxacin, ceftazidime and gentamicin. The Proteus spp.isolated was resistant to ceftazidime, amoxicillin clavulanic acid and Trimethoprim/sulphamethaxazole (TMP/SMX).

\section{Discussion}

Demographic and clinical characteristics of patients The contribution of antibiotic single agent perioperative prophylaxis to reduce SSIs for most surgical procedures 
Table 1 Background epidemiological parameters of patients issued with single dose antibiotic prophylaxis during elective orthopedic surgery

\begin{tabular}{|c|c|c|c|}
\hline Variable & $\begin{array}{l}\text { Ceftriaxone } \\
\text { (Group A) } \\
N=113\end{array}$ & $\begin{array}{l}\text { Cefepime } \\
\text { (Group B) } \\
N=117\end{array}$ & $p$-value \\
\hline \multicolumn{4}{|l|}{ Age (years) } \\
\hline Median & 29 & 30 & \multirow[t]{2}{*}{0.3229} \\
\hline IQR & $14-40$ & $21-40$ & \\
\hline \multicolumn{4}{|l|}{ Age group } \\
\hline$<21$ years & $40(35.40 \%)$ & $29(24.79 \%)$ & \multirow[t]{4}{*}{0.292} \\
\hline $21-40$ years & $48(42.48 \%)$ & $60(51.28 \%)$ & \\
\hline $41-60$ years & $23(20.35 \%)$ & $24(20.51 \%)$ & \\
\hline$>60$ years & $2(1.77 \%)$ & $4(3.42 \%)$ & \\
\hline \multicolumn{4}{|l|}{ Sex } \\
\hline Males & 77 (68.1\%) & $81(69.2 \%)$ & \multirow[t]{2}{*}{0.562} \\
\hline Females & 36 (31.9\%) & $32(30.8 \%)$ & \\
\hline \multicolumn{4}{|l|}{ Level of education } \\
\hline Primary & $56(49.6 \%)$ & $56(47.9 \%)$ & \multirow[t]{4}{*}{0.859} \\
\hline Secondary & $44(38.9 \%)$ & $48(41.0 \%)$ & \\
\hline Tertiary & $9(8.0 \%)$ & $8(6.8 \%)$ & \\
\hline Informal & $4(3.5 \%)$ & $5(4.3 \%)$ & \\
\hline \multicolumn{4}{|l|}{ Occupation } \\
\hline Employed & $38(33.63 \%)$ & $39(33.33 \%)$ & \multirow[t]{3}{*}{0.095} \\
\hline Unemployed & 35 (30.97\%) & $50(42.74 \%)$ & \\
\hline Dependant & $40(35.40 \%)$ & $28(23.93 \%)$ & \\
\hline \multicolumn{4}{|l|}{$\begin{array}{l}\text { Mode of Health } \\
\text { Care Financing }\end{array}$} \\
\hline Out of Pocket & $90(79.65 \%)$ & $91(77.78 \%)$ & \multirow[t]{2}{*}{0.729} \\
\hline Health Insurance & $23(20.35 \%)$ & $26(22.22 \%)$ & \\
\hline
\end{tabular}

is established. However, optimal use of prophylactic antimicrobial agents does not obviate other factors such as meticulous attention to basic infection-control strategies. The present study did not define age, gender, or mechanism of injury as significant risk factors associated with SSIs. These findings are in agreement with Maksimovic et al. [2] and Graf et. al [24] who found no significant association in age or gender between case patients and their matched interventions. However, in a recent Egyptian study, it was reported age above 68 years to be a risk factor for SSIs among 93 orthopedic patients [25]

Recently, the contribution of prolonged pre-operative duration hospital stay of $13.6 \pm 1.6$ days and duration of operation beyond $75^{\text {th }}$ percentile for procedure have been strongly linked to increase SSI in orthopedic surgery (Khaleid et al. [25]. In the present study, there was a statistically significant difference in participants distribution in two groups regarding time spent in hospital before treatment and the anatomical site of the lesion. Despite majority of patients in ceftriaxone group stayed
Table 2 Pre- operative parameters of patients subjected to prophylactic single dose regimen during elective orthopedic surgery

\begin{tabular}{|c|c|c|c|}
\hline \multirow[t]{2}{*}{ Variable } & $\begin{array}{l}\text { Ceftriaxone } \\
\text { (Group A) }\end{array}$ & $\begin{array}{l}\text { Cefepime } \\
\text { (Group B) }\end{array}$ & \multirow[t]{2}{*}{$p$-value } \\
\hline & $N=113$ & $N=117$ & \\
\hline \multicolumn{4}{|l|}{ Indication for surgery } \\
\hline Trauma related & $91(80.53 \%)$ & $100(85.47 \%)$ & \multirow[t]{2}{*}{$0.31 \varepsilon$} \\
\hline Non-Trauma Related & $22(19.47 \%)$ & $17(14.53 \%)$ & \\
\hline \multicolumn{4}{|c|}{ Anatomical location of lesion } \\
\hline Upper Limb & $44(38.9 \%)$ & $30(26.6 \%)$ & \multirow[t]{2}{*}{0.03} \\
\hline Lower limb & $69(61.1 \%)$ & $87(74.4 \%)$ & \\
\hline \multicolumn{4}{|l|}{ Time to treatment } \\
\hline Less than 2 weeks & $29(25.7 \%)$ & $48(41.0 \%)$ & \multirow[t]{2}{*}{0.014} \\
\hline More than 2 Weeks & $84(74.3 \%)$ & 69 (59.0 \%) & \\
\hline \multicolumn{4}{|l|}{ History of antibiotic use } \\
\hline None & $84(74.3 \%)$ & $81(69.2 \%)$ & \multirow[t]{2}{*}{0.39} \\
\hline More than 7 days & $29(25.7 \%)$ & $36(30.8 \%)$ & \\
\hline \multicolumn{4}{|c|}{ Type of elective procedure } \\
\hline Invasive & $93(82.3 \%)$ & $104(88.9 \%)$ & \multirow[t]{2}{*}{0.154} \\
\hline Non Invasive & $20(17.7 \%)$ & $13(11.1 \%)$ & \\
\hline
\end{tabular}

significantly longer in the hospital before treatment less SSI was observed in this group. Overwhelmed surgical systems and resource poor setting may explain prolonged hospital stay whereas lower limb lesions predominate since it is the most common injury incurred by motorcycle accidents victims in our setting [26].

\section{Incidence of superficial surgical site infection}

This study demonstrated that the cumulative incidence of superficial SSI after intervention among the participants was comparable to rates detected in some developing countries [4, 27-29]. While in this study ceftriaxone arm showed a lower cumulative incidence compared to cefepime arm, the difference was not statistically significant. These findings are in tandem with landmark studies and meta-analysis reviews that pegged effects of a single agent perioperative prophylaxis in reduction of SSI incidence rate to a range between 0 to $8 \%$ among patients who underwent elective orthopedic surgery. Comparatively, and in consideration of cefepime and ceftriaxone head-to-head non-orthopedic comparative multicenter trial in Parma Italy the study reported the SSI incidence of $2.3 \%$ for ceftriaxone group and $1.1 \%$ in the cefepime group. However, the difference of SSIs among 209 participants was not statistically different [18]. Using similar methodology in the present study, the incidence nearly doubled, which speculatively may be attributed to wound class and target organism selectivity in orthopedics compared to biliary surgery. 
Table 3 Selected intra-operative considerations of patients subjected to single dose regimen during elective orthopedic surgery

\begin{tabular}{|c|c|c|c|}
\hline \multirow[t]{2}{*}{ Variable } & $\begin{array}{l}\text { Ceftriaxone } \\
\text { (Group A) }\end{array}$ & $\begin{array}{l}\text { Cefepime } \\
\text { (Group B) }\end{array}$ & \multirow[t]{2}{*}{$p$-value } \\
\hline & $N=113$ & $N=117$ & \\
\hline \multicolumn{4}{|l|}{ Hemoglobin Level } \\
\hline Mean & $11.6 \mathrm{~g} / \mathrm{dl}$ & $11.3 \mathrm{~g} / \mathrm{dl}$ & \multirow[t]{3}{*}{0.577} \\
\hline Range & $6-17.2 \mathrm{~g} / \mathrm{dl}$ & $5.8-16 \mathrm{~g} / \mathrm{dl}$ & \\
\hline SDEV & $2.17 \mathrm{~g} / \mathrm{dl}$ & $2.10 \mathrm{~g} / \mathrm{dl}$ & \\
\hline \multicolumn{4}{|c|}{ Timing of prophylaxis [within] } \\
\hline$<15 \min$ & 65 (56 \%) & 57 (48.7 \%) & \multirow[t]{4}{*}{0.408} \\
\hline$>16-<30 \mathrm{~min}$ & $43(38.0 \%)$ & $54(46.2 \%)$ & \\
\hline$>31-<45 \min$ & $5(6.0 \%)$ & $6(5.1 \%)$ & \\
\hline$>46<60 \mathrm{~min}$ & 0 & 0 & \\
\hline \multicolumn{4}{|c|}{ Approximate blood loss } \\
\hline Less than $400 \mathrm{ml}$ & $93(82.3 \%)$ & $88(75.2 \%)$ & \multirow[t]{2}{*}{0.189} \\
\hline More than $400 \mathrm{ml}$ & $20(17.7 \%)$ & $29(24.20 \%)$ & \\
\hline \multicolumn{4}{|c|}{ Duration of operation [within] } \\
\hline$<1 \mathrm{~h}$ & $60(53.1 \%)$ & $58(49.6 \%)$ & \multirow[t]{4}{*}{0.864} \\
\hline $2 \mathrm{~h}$ & $43(38.1 \%)$ & 45 (38.5\%) & \\
\hline $3 \mathrm{~h}$ & $9(8.0 \%)$ & $13(11.1 \%)$ & \\
\hline 4 or More hours & $1(0.8 \%)$ & $1(0.8 \%)$ & \\
\hline \multicolumn{4}{|l|}{ ASA Classification } \\
\hline ASA 1 & 105 (92.92 \%) & $102(87.18 \%)$ & \multirow[t]{3}{*}{0.116} \\
\hline ASA 2 & $7(6.19 \%)$ & $15(12.82 \%)$ & \\
\hline ASA 3 & $1(0.88)$ & 0.00 & \\
\hline
\end{tabular}

However, authors in the Italian study attributed the apparently low SSI incidence to a zwitterionic oxymino $\beta$ lactam amino-thiazole side chain- a chemical peculiarityof cefepime rather than other study factors.

The present study also showed a low cumulative SSI incidence in contrast to the outcomes of recent descriptive studies, which reported high SSIs cumulative incidence within disaggregated wound class. Recently in Egypt, Khaleid et al. [25] reported an cumulative orthopedic SSI incidence rate of $25.8 \%(4.1 \%$ in clean wounds). More so, Maksimovic et al. [2] and Graf et al. [24] reported an overall orthopedic SSI incidence of $22.7 \%(13.2 \%$ in clean wounds) and $22.5 \%$ respectively in their studies. These studies among many other reasons attributable to higher incidences of orthopedic SSI reported failed tostate or show whether the researchers used perioperative prophylaxis among the participants.

\section{Comparison of single dose efficacy between cefepime and ceftriaxone}

This study showed a lower incidence rate of SSIs per 1000 days in ceftriaxone group and nearly twice the rate
Table 4 Selected post-operative characteristics in patients subjected to perioperative single dose regimen

\begin{tabular}{|c|c|c|c|}
\hline \multirow[t]{2}{*}{ Variable } & $\begin{array}{l}\text { Ceftriaxone } \\
\text { (Group A) }\end{array}$ & $\begin{array}{l}\text { Cefepime } \\
\text { (Group B) }\end{array}$ & \multirow[t]{2}{*}{$P$-value } \\
\hline & $N=113$ & $N=117$ & \\
\hline \multicolumn{4}{|c|}{ Increasing tenderness } \\
\hline Absent & 111 (98.23 \%) & 113 (96.58 \%) & \multirow[t]{3}{*}{0.81} \\
\hline Present & $1(0.9 \%)$ & $3(2.6 \%)$ & \\
\hline Indeterminate & 1 (0.9 \%) & 1 (0.9\%) & \\
\hline \multicolumn{4}{|l|}{ Morbid fever } \\
\hline Absent & 112 (99.12 \%) & 112 (95.73 \%) & \multirow[t]{4}{*}{0.122} \\
\hline Present & $0(0.00 \%)$ & $4(3.43 \%)$ & \\
\hline \multirow[t]{2}{*}{ Indeterminate } & $1(0.9 \%)$ & 1 (0.9\%) & \\
\hline & 0 & 0 & \\
\hline \multicolumn{4}{|c|}{ Wound dehiscence } \\
\hline Present & $3(2.65 \%)$ & $5(4.27 \%)$ & \multirow[t]{2}{*}{0.380} \\
\hline Absent & 110 (97.35 \%) & 112 (95.73 \%) & \\
\hline \multicolumn{4}{|c|}{ Occupied Bed Days } \\
\hline $1-5$ days & $68(60.2 \%)$ & $58(49.6 \%)$ & \multirow[t]{3}{*}{0.211} \\
\hline $6-10$ days & $43(38.0 \%)$ & 45 (38.5\%) & \\
\hline 11-15 days & $2(1.80 \%)$ & $13(11.1 \%)$ & \\
\hline \multicolumn{4}{|c|}{ Primary outcome (SSI) } \\
\hline Absent & 110 (97.35\%) & 112 (95.73 \%) & \multirow[t]{2}{*}{0.380} \\
\hline Present & $3(2.65 \%)$ & 5 (4.27\%) & \\
\hline
\end{tabular}

in cefepime group, although the difference was not statistically significant. The difference in the incidence rate per 1000 days in the cefepime group could not be attributed or explained on theoretical grounds or its molecular profile -as a fourth generation cephalosporins the same as speculated by Yeap et al. [30]. The spectrum differences may not explain the difference since both have a near preponderance to gram-negative organism.

The Incidence Rate Ratio of less than 1.0 was observed in this study and underscored an overall picture of substantial effect of cefepime and ceftriaxone in reducing the incidence of clean orthopedic surgical site infection, despite of spectrum and selectivity limitations. Other studies conducted involved comparison between second or third generation cephalosporins and documented similar trends on the reduction of SSI incidence rate in orthopedic surgery $[8,31,32]$. However, there might be fewer studies published comparing cefepime with other generations of cephalosporins, despite its documented use as perioperative prophylaxis during orthopedic surgery $[3,30]$.

Ceftriaxone and cefepime are both known to have excellent bioavailability and in this study, a single dose of $50 \mathrm{mg} / \mathrm{kg}$ in pediatric population and up to $2 \mathrm{~g}$ intravenous infusion among adults was given optimally. The cost implication between cefepime and ceftriaxone was 


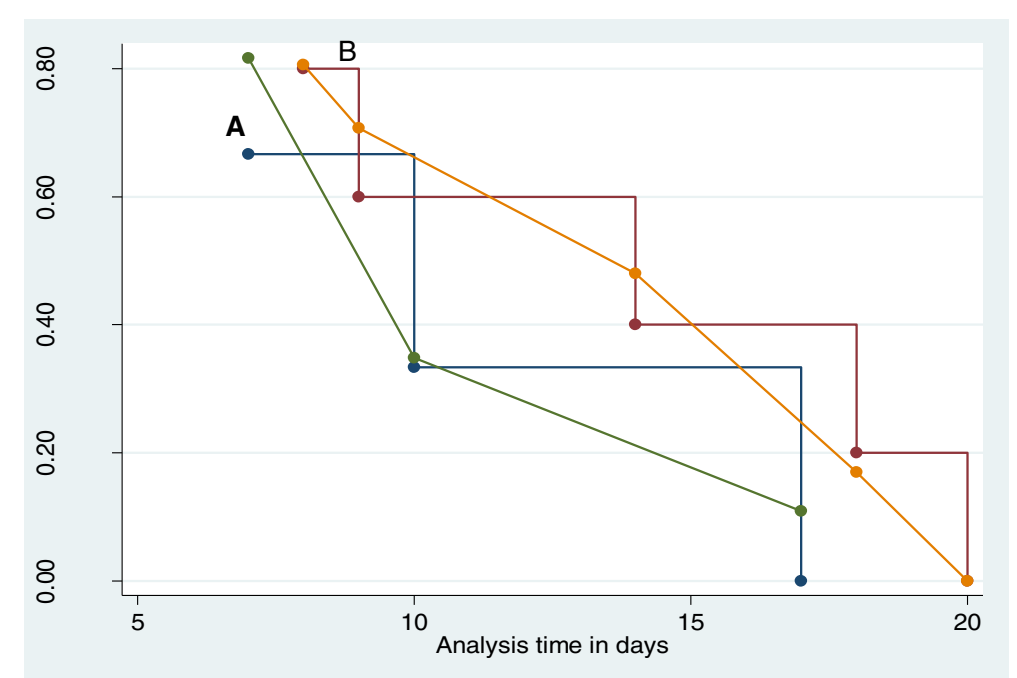

Fig. 2 Kaplan-Cox-Meier probability estimates of developing (surviving) superficial surgical site infection in elective orthopedic surgery a: Ceftriaxone, $\mathbf{b}$ Cefepime

vast and at the time of this study, the cost of $2 \mathrm{~g}$ ceftriaxone was USD 1.20 compared to USD 12.80 (ten times less) for $2 \mathrm{~g}$ of Cefepime. Therefore, the acquisition cost of ceftriaxone was quite substantially lower than cefepime as a single dose prophylaxis.

The findings also compares well to a Cost Benefit Analysis study by Mazza [33] involving 477 consecutive patients who received ceftriaxone before undergoing orthopedic surgery which reported that a single dose ceftriaxone given prophylactically was a cost-effective measure compared to placebo based on infection incidence and length of hospital stay.

The etiological agents of superficial SSI in ceftriaxone and cefepime groups

In the present study, it was observed that the predominant organisms causing SSIs after clean procedures in ceftriaxone group were Staphylococcus aureus, Coagulasenegative staphylococci, andPseudomonas aeruginosa. While in cefepime regimen, bacteriological isolates were Staphylococcus aureus, Coagulase negative Staphylococcus, Proteus spp., and Klebsiella pneumoniae. These findings were congruent with studies conducted at BMC by Mawalla et al. [1] and Khaleid et al. [25]. A similar observation was made by USNational Healthcare Safety Network, January 2006-October 2007 while reporting on distribution of pathogens related to orthopedic surgery [34].

The isolation of Staphylococcus aureus among both study groups is in agreement with observations made by the New York State 2009 report where Staphylococcus aureus accounted for $59.8 \%$ of total isolates in orthopedic surgical site infections [35]. A possible explanation for Staphylococcus aureus being a dominant cause ofwound infection in orthopedic surgeryis generally correlated to admission from a healthcare facility and nasal carriage of Staphylococcus aureus [36].

During this study infection due to other Staphylococcus spp., isolates had a late presentation post operatively concurrently with Pseudomonas aeruginosa; a trend also noted by Moss et al. [37]. The drug sensitivity and resistance pattern of bacterial isolates did not differ among groups and were broadly resistant to $\beta$ lactams, and were all sensitive to gentamicin and ciprofloxacin.

\section{Conclusion}

Though relatively more SSIs were observed when single dose of cefepime was used for prophylaxis in elective orthopedic surgery compared to ceftriaxone this was not statistically significant. Staphylococcus aureus and gram-

Table 5 Rate of superficial surgical site infection and drug efficacy in elective surgery

\begin{tabular}{llllll}
\hline Study group & $\begin{array}{l}\text { Number } \\
\text { evaluated }\end{array}$ & $\begin{array}{l}\text { Number } \\
\text { infected }\end{array}$ & '000 person days & IR & IRR (95 \% CI) \\
\hline Group A & 113 & 3 & 3324 & 0.9 & $0.62(0.26-1.37)$ \\
Group B & 117 & 5 & 3429 & 1.5 & 0.318 \\
\hline
\end{tabular}

$I R$ Incidence Rate (i.e. number per 1000 person days), IRR Incidence Rate Ratio 
negative bacteria depicting resistance to $\beta$-lactam based antibiotics are the dominant etiological agents causing superficial surgical infection in elective orthopedic surgery at BMC.

\section{Abbreviations}

BMC: Bugando Medical Centre; CDC: Centre for Disease Control; SSI: Surgical Site Infection; SOPD: Surgical Outpatient Patient Department; PI: Principal Investigator; CUHAS: Catholic University of Health \& Allied Science; GCP: good clinical practice.

\section{Competing interests}

The authors declare that they have no competing interests. Funding has been received from the Ministry of Health, United Republic of Tanzania, as an unrestricted educational grant for a postgraduate thesis.

\section{Authors' contributions}

JMM, IHN and SEM provided major contributions in concept, study design and literature review. JMM performed data collection, entry and drafting of manuscript. JS performed laboratory procedures. IHN, JS and SEM contributed towards writing of manuscript and availing of literature. All authors approved the final manuscript to be submitted.

\section{Acknowledgements}

We would like to thank Dr. Nkinda Mbelenge, Dr. Ramesh Das, and Dr Benson Kidenya (BMC/CUHAS), for their technical support under different capacities.

Much appreciation to all my research assistants, members of the Orthopedic and Trauma Wards, Surgical Outpatient Clinic staff, and Microbiology Laboratory Unit for all their unequivocal assistance to get our data collected.

\section{Author details}

'Department of Surgery, Catholic University of Health and Allied Sciences, Box 1464, Mwanza, Tanzania. ${ }^{2}$ Department of Trauma and Orthopedics, Bugando Medical Centre, Box 1370, Mwanza, Tanzania. ${ }^{3}$ Department of Microbiology/Immunology, Catholic University of Health and Allied Sciences (CUHAS), P.O. BOX 1464, Mwanza, Tanzania.

\section{Received: 2 September 2015 Accepted: 18 November 2015} Published online: 23 December 2015

\section{References}

1. Mawalla B, Mshana SE, Chalya PL, Imirzalioglu C, Mahalu W. Predictors of surgical site infections among patients undergoing major surgery at Bugando Medical Centre in Northwestern Tanzania. BMC Surg. 2011;11:21.

2. Maksimovic J, Markovic-Denic L, Bumbasirevic M, Marinkovic J, Vlajinac H. Surgical site infections in orthopedic patients: prospective cohort study. Croat Med J. 2008;49(1):58-65.

3. Yalcin AN, Erbay RH, Serin S, Atalay H, Oner O. Perioperative antibiotic prophylaxis and cost in a Turkish University Hospital. Le Infezioni in Medicina. 2007;2:99-104.

4. Thu LT, Dibley MJ, Ewald B, Tien NP, LD L. Incidence of surgical site infections and accompanying risk factors in Vietnamese orthopaedic patients. J Hosp Infect. 2005;60(4):360-7.

5. Costerton JW. Biofilm theory can guide the treatment of device-related orthopedic infections. Clin Orthop Related Res. 2005;437:7-11.

6. Whitehouse JD, Friedman ND, Kirkland KB, Richardson WJ, Sexton DJ. The impact of surgical-site infections following orthopedic surgery at a community hospital and a university hospital: adverse quality of life, excess length of stay, and extra cost. Infect Control Hosp Epidemiol. 2002;23:183-9.

7. Treatment guidelines: Antimicrobial prophylaxis in surgery. Med Lett. 2009; 7(82):47-52.

8. ASHP. Therapeutic guidelines on antimicrobial prophylaxis in surgery. Am J Health-Syst Pharm. 2013;70:195-283.

9. Periti P, Jacchia E. Ceftriaxone as Short-Term Antimicrobial Chemoprophylaxis in Orthopedic Surgery: a 1-Year Multicenter Follow-Up preliminary Results of a Controlled Multicentre Study. Eur Surg Res. 1989;21:25-32.

10. Boxma H, Broekhuizen T, Patka P. Randomised controlled trial of single-dose antibiotic prophylaxis in surgical treatment of closed fractures: the Dutch Trauma Trial. Lancet. 1996;347:1133-7.
11. Gosselin RA, Roberts I, Gillespie WJ. Antibiotics for preventing infection in open limb fractures. Cochrane Database Syst Rev. 2004;1:CD003764.

12. Jaeger M, Maier D, Kern W. Antibiotics in trauma and orthopedic surgery-a primer of evidence based recommendations. Injury. 2006;37:74-80.

13. Gillespie WJ, Walenkamp GHIM. Antibiotic prophylaxis for surgery for proximal femoral and other closed long bone fractures. Cochrane Database Syst Rev. 2010;3:CD000244.

14. al Harbi M. Antimicrobial prophylactic practice in surgical patients. East Afr Med J. 1998;75:703-7.

15. Bugando Medical Centre. Health management and information systems. In: MUTUHA BMC. Mwanza: Bugando Medical Centre; 2013.

16. Altman DG. Statistics and ethics in medical research III How large a sample? Br Med J. 1980;281:1336-8.

17. Noordzij M, Tripepi G, Dekker FW, Zoccali C, Tanck MW, Jagger KJ. Sample size calculations: basic principles and common pitfalls [Erratum]. Nephrol Dial Transplant 2010;25:1-6.

18. Del Rio P, Vellone M, Fragapane P. Cefepime for prophylaxis of infections in the surgery of cholelithiasis. Results of a multi-centric comparative trial. Acta Biomed. 2008;79(1):23-7.

19. Mangram AJ, Horan TC, Pearson ML, Silver LC, Jarvis WR. Guideline for prevention of surgical site infection, 1999. Hospital Infection Control Practices Advisory Committee. Infect Control Hosp Epidemiol. 1999;20:250-80.

20. Koneman E, Allen S, Janda W, Schreckenberger PP. Color Atlas and Textbook of Diagnostic Microbiology. 5th ed. PA Lippincott: Lippincott, Williams \& Wilkins Publishers; 1997.

21. Mshana SE, Kamugisha E, Mirambo M, Lyamuya EF. Prevalence of multi resistnat gram negative organism in a tertiary hospital in Mwanza Tanzani. BMC Res Notes. 2009;2:49.

22. Mshana SE, Kamugisha E, Mirambo M, Rambau P, Chalya P, Mahalu W, et al. Prevalence of clindamycin inducible resistance among methicillin-resistant Staph aureus at Bugando Medical Centre Mwanza Tanzania. Tanzan J Health Res. 2009;11(2):59-64.

23. Wayne PA. Clinical and Laboratory Standards Institute(CLSI): Performance standards for antimicrobial disk susceptibility tests. 19th edition Approved standard. CLSI Document 2009, M100-S19:29.

24. Graf K, Sohr D, Haverich A, Kühn C. Decrease of deep sternal surgical site infection rates after cardiac surgery by a comprehensive infection control program. icvt. 2009;9:282-6.

25. Khaleid M, Haleim A, Zein K. ET: Surgical Site Infections and Associated Risk Factors in Egyptian Orthopedic patients. J Am Sci. 2010;6(7):272-80

26. Chalya PL, Mabula JB, Ngayomela IH, Kanumba ES, Chandika AB, Giiti G, et al. Motorcycle Injuries as an Emerging Public Health Problem in Mwanza City, North-Western Tanzania. Tanzan J Health Res. 2010;12(4):214-21

27. Kasatpibal N, Jamulitrat S, M'-Irrazi VMB, Sellies J, Berrichi A. Prospective study of operative site infections observed over four-year period: Analysis of 8811 orthopedic surgery procedures. J Bone Joint Surg Br Volume. 2005;90B(Supp_II):264.

28. Gastmeier P, Sohr D, Brandt C. Redution of orthopedic wound infections in 21 hospitals. Arch Orthop Trauma Surg. 2005;125:526-30.

29. Alicia IH, Edwards JR, Patel MJ. Antimicrobial-Resistant Pathogens Associated With Healthcare Associated Infections: Annual Summary of Data Reported to the National Healthcare Safety Network at the Centers for Disease Control and Prevention, 2006-2007. Infect Control Hosp Epidemiol. 2008;29:996-1011.

30. Yeap JS, Lim JW, Vergis SM, Young PS, Chiu CK, Singh H. Prophylactic Antibiotics in Orthopedic Surgery: Guidelines and Practice. Med J Malaysia. 2006;61:181-8

31. Steinberg J, Braun B, Hellinger WC, Kusek L, Bozikis MR, Bush AJ. Trial to Reduce Antimicrobial Prophylaxis Errors (TRAPE) Study Group. Ann Surg. 2009:250(1):10-6.

32. Slobogean GP, O'brien PJ, Brauer CA. Single-dose versus multiple dose antibiotic prophylaxis for the surgical treatment of closed fractures. Acta Orthop. 2010;81:256-62.

33. Mazza A. Ceftriaxone as short-term antibiotic prophylaxis in orthopedic surgery: a cost-benefit analysis involving 808 patients. J Chemother. 2000; 3:29-33.

34. Hidron Al, Edwards JR, Patel J. Antimicrobial-resistant pathogens associated with healthcare-associated infections 2006-2007. Infect Control Hosp Epidemiol. 2008;29:996-1011. 
35. Department NYSH: Hospital Acquired infections, New York State 2009. http://www.health.state.ny.us/statistics/facilities/hospital/hospital_acquired_ infections/.

36. Berthelot P, Grattard F, Cazorla C, Passot JP, Fayard JP, Meley R. Is nasal carriage of Staphylococcus aureus the main acquisition pathway for surgical-site infection in orthopaedic surgery? Eur J Clin Microbiol Infect Dis. 2010;29(4):373-82.

37. Moss R, Green L, Mills, Sposato K, Vignari. Guide to the Elimination of Orthopedic Surgical Site infections. An APIC Guide. 2010; 4-65.

Submit your next manuscript to BioMed Central and we will help you at every step:

- We accept pre-submission inquiries

- Our selector tool helps you to find the most relevant journal

- We provide round the clock customer support

- Convenient online submission

- Thorough peer review

- Inclusion in PubMed and all major indexing services

- Maximum visibility for your research 